\title{
Ultrastructural study of Mycobacterium avium infection of HT-29 human intestinal epithelial cells
}

\author{
FELIX J . SANGARI, J OSEPH R. GOODMAN* and LUIZ E. BERMUDEZ \\ Kuzell Institute for Arthritis and Infectious Diseases, San Francisco, CA 94115 and *Pediatric Department \\ Electron Microscopy, University of California - San Francisco, San Francisco, CA 94143, USA
}

\begin{abstract}
Mycobacterium avium is a common pathogen in AIDS patients and, in a large percentage of those patients, $M$. avium infection appears to be acquired via the gastrointestinal tract. $M$. avium is able to bind to and enter human and murine intestinal epithelial cells in vitro and in vivo. The invasion by and intracellular fate of $M$. avium in the HT-29 intestinal epithelial cell line was examined in an ultrastructural study. Bacterial contact with polarised cells was observed 10-15 min after monolayer infection and in polarised monolayers this always occurred in areas lacking microvilli. Contact with HT-29 cells did not appear to take place in a preferential area on the bacterial cell. Following invasion, M. avium was encountered within vacuoles containing either single or multiple bacteria; the latter evolved to contain only an individual bacterium. Vacuoles containing more than one bacterium were seen early in the infection and eventually underwent segmentation, with each bacterium occupying a vacuole. No bacteria were observed outside vacuoles up to 5 days after infection.
\end{abstract}

\section{Introduction}

Mycobacterium avium can cause disseminated disease in patients with AIDS and pulmonary disease in nonAIDS patients [1-3]. Sufficient evidence exists to suggest that the gastrointestinal (GI) tract is the major route of infection in patients with AIDS [4], although the respiratory tract appears to be the route of infection in a small percentage of cases [5]. Therefore, a critical step in the pathogenesis of $M$. avium infection is the crossing of the intestinal mucosa. Previous studies have shown that $M$. avium can bind to and enter intestinal mucosal cells in vitro and in vivo [6-8]. Investigations in mice have determined that $M$. avium invades the intestinal mucosa primarily through enterocytes, although the role of $M$ cells in the interaction of the bacterium with the intestinal mucosa cannot be ruled out [9]. In contrast, it has been shown previously that other mycobacteria, such as $M$. bovis BCG, invade the intestinal mucosa by interacting with $M$ cells [10]. It has also been demonstrated that $M$. avium can multiply intracellularly in intestinal cells in vitro [6]; however, how $M$. avium enters intestinal cells and the fate of the organism once within intestinal epithelial cells is unclear. Studies in macrophages have determined that

Received 29 A pril 1999; revised version received 1 July 1999; accepted 27 July 1999.

Corresponding author: Dr. L. E. Bermudez.
M. avium lives within a vacuole that fails to fuse with a lysosome or to acidify [11].

The HT-29 human intestinal cell line is an enterocyte cell line that expresses typical enterocyte differentiation and polarisation when cultured in the presence of galactose $[8,12]$. The use of differentiated cell lines has been very useful in understanding the attachment and invasion mechanisms of intestinal pathogens such as Salmonella [13], Shigella [14] and Listeria monocytogenes [15]. The present study investigated the ultrastructural process of $M$. avium invasion and intracellular fate within HT-29 intestinal epithelial cells in vitro.

$M$ aterials and methods

M ycobacteria

M. avium strains 101 (serovar 1) and 104 were used in the studies. Strain 101 was originally isolated from the blood of an AIDS patient and has been well characterised and used in several laboratories worldwide [16]. The $M$. avium strains were cultured on plates of Middlebrook $7 \mathrm{H} 11$ medium supplemented with oleic acid, albumin, dextrose and catalase for 10 days. Transparent colonies were obtained, suspended in $7 \mathrm{H} 9$ broth and incubated for 5 days to the logarithmic phase of growth, as reported previously [8]. Bacteria 
were then washed twice in Hanks's Balanced Salts Solution (HBSS) and the final suspension was adjusted to $5 \times 10^{7}$ bacteria/ml by the McFarland turbimetric standard. The bacterial suspension was then passed through a 27-gauge needle 10 times and vortex mixed for $2 \mathrm{~min}$. The suspension was allowed to settle at room temperature for $5 \mathrm{~min}$ and the upper third was collected, stained by acid-fast stain and observed by light microscopy to ensure bacterial dispersion. Viability of the bacterial suspension was determined by plating the inoculum on to $7 \mathrm{H} 11$ agar plates.

\section{HT-29 cells and invasion assay}

HT-29 intestinal cells were maintained in McCoy's tissue culture medium (Difco Laboratories, Detroit, M I, USA) supplemented with galactose $1 \%, 2 \mathrm{~mm}$ glutamine and fetal bovine serum (Sigma) $10 \%$ and incubated at $37^{\circ} \mathrm{C}$ with $\mathrm{CO}_{2} 5 \%$. Cells were used between passage 20 and 30. Six-well tissue culture plates were seeded with HT-29 cells at $1 \times 10^{5}$ cells/well and the cells were allowed to grow until $80 \%$ semi-confluence.

The HT-29 monolayers were exposed to $1 \times 10^{7}$ bacteria suspended in HBSS for $1 \mathrm{~h}$ and the monolayers were then washed extensively to remove extracellular bacteria. Monolayers were incubated for different periods of time and then fixed with glutaraldehyde, as described below, for thin-section transmission electron microscopy $[17,18]$.

In some studies, HT- 29 cells ( $10^{5}$ cells) were seeded on a transwell membrane with pores of $3 \mu \mathrm{m}$ diameter. Cells were allowed to grow to confluence and the transmembrane resistance of the monolayers was monitored daily. Monolayers were used when resistance reached $c$. $400 \mathrm{ohm} \times \mathrm{cm}^{2}$. M onolayers were infected by adding $1 \times 10^{7} \mathrm{M}$. avium to the top chamber for $1 \mathrm{~h}$, followed by washing to remove the extracellular bacteria.

\section{Transmission electron microscopy}

A 1-ml bacterial suspension was added to each well of a six-well tissue culture plate (Costar, Cambridge, MA, USA) of the top chamber of a transwell monolayer. These plates were then incubated at $37^{\circ} \mathrm{C}$ in the presence of $\mathrm{CO}_{2} 5 \%$. At $30 \mathrm{~min}, 1 \mathrm{~h}, 1,2,5$ and 10 days, cells were washed with HBSS, fixed in buffered glutaraldehyde $2.5 \%$ for $1 \mathrm{~h}$, post-fixed for $1 \mathrm{~h}$ at $4^{\circ} \mathrm{C}$ with osmium tetroxide $2 \%$ and washed with distilled water. Small segments were then dehydrated through ethyl alcohol 50 and $80 \%$ at room temperature, embedded in LR white resin $[17,18]$ and polymerised at $52^{\circ} \mathrm{C}$. Thin sections were cut and stained with uranyl acetate and lead citrate. Electron micrographs were obtained with a Philips 201 transmission electron microscope. To infect the transwell monolayer, $10^{7}$ $M$. avium cells were added to the top chamber and at $15 \mathrm{~min}, 30 \mathrm{~min}$ and $1 \mathrm{~h}$ the transwell membrane was fixed with glutaraldehyde $2 \%$ for $30 \mathrm{~min}$, cut out of the plastic, embedded in resin, and processed for electron microscopy as described previously [18].

\section{Results}

All the figures show results with $M$. avium strain 101 because the results with strain 104 were indistinguishable from those obtained with strain 101. Fig. 1a and $b$ show the interaction between $M$. avium and polarised HT-29 cells 15 min after infection. M. avium was first observed invading HT-29 cells after incubation for 30 min. (Fig. 1c). Bacterial internalisation followed a response from the epithelial cells (cell pit formation, Fig. $1 a, b$ and c). M. avium was seen in contact with epithelial cells only in areas lacking microvilli, an observation that agrees with an observation previously made in vivo $[7,9]$ (unpublished observations).

M. avium infection of HT-29 cells was followed for up to 5 days. At all the time points, bacteria were contained within well-defined vacuoles. At $24 \mathrm{~h}$ after uptake, a large number of mitochondria and other cell organelles were lying close to the vacuole membrane, polarised towards the site where the bacterium was encountered in the cell (Fig. 2). This finding could be a consequence of adherence of mitochondria to the bacterial vacuole, thus explaining why mitochondria were encountered in close proximity to the bacterial vacuole in the cytoplasm. This phenomenon was observed in approximately two-thirds of HT-29 cells infected for 24 and $48 \mathrm{~h}$, but was not seen in cells infected for 5 days. A number of intracellular organelles other than mitochondria were seen also in the same area of the cells where bacterial vacuoles were located.

In HT-29 cells infected for $48 \mathrm{~h}$, bacterial vacuoles were seen undergoing segmentation. Large vacuoles, initially with more than one bacterium, divided into several small vacuoles containing a single bacterium within $48 \mathrm{~h}$ after infection (Fig. $3 \mathrm{a}, \mathrm{b}$ and $\mathrm{c}$ ).

Five days after infection, large numbers of bacteria were observed intracellularly, although vacuoles with more than one organism were rarely seen (Fig. $4 a, b)$. Some bacteria were observed to be undergoing replication (Fig. 4c).

During the 5-day infection period, $M$. avium was always seen within vacuoles and not free in the cytoplasm. Close visualisation of the $M$. avium vacuole in some cases (Fig. 5) shows the presence of intravacuolar material, which is probably similar to that reported previously.

\section{Discussion}

These results demonstrate that $M$. avium makes initial contact with intestinal epithelial cells by triggering 

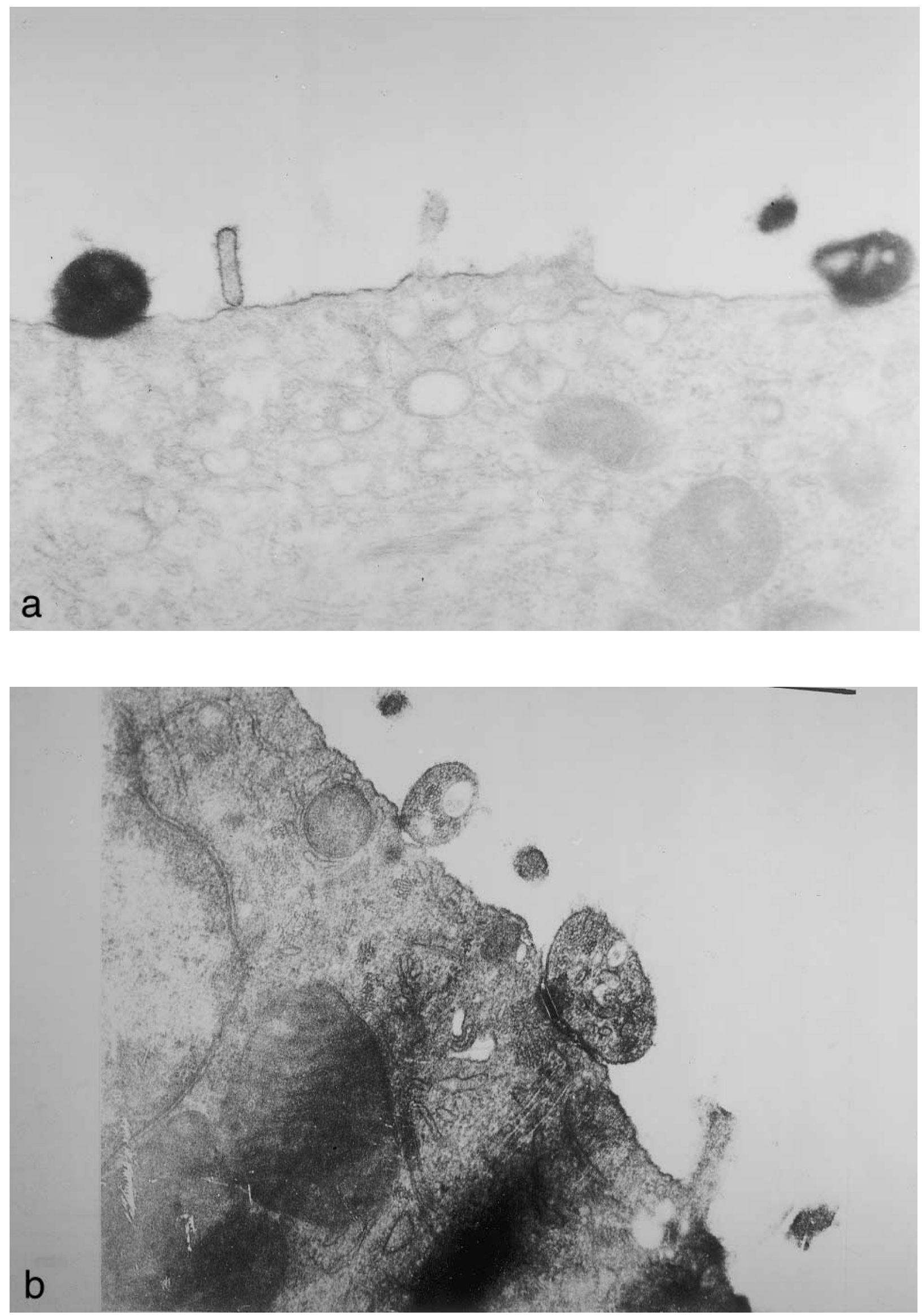

Fig. 1. Electron micrographs illustrating M. avium uptake by HT-29 cells. M. avium are in contact with transmembrane polarised HT-29 cells $(a, 52000 \times ; b, 78000 \times)$ and being engulfed by an HT-29 cell cultured on plastic (c) $(8250 \times)$. The protrusions of the intestinal cell were observed to be asymmetrical. No microvilli were observed in the area of contact between M. avium and HT-29 cells. A rrow-heads show (c) the bacteria being engulfed by HT-29 cells. 


\section{C}

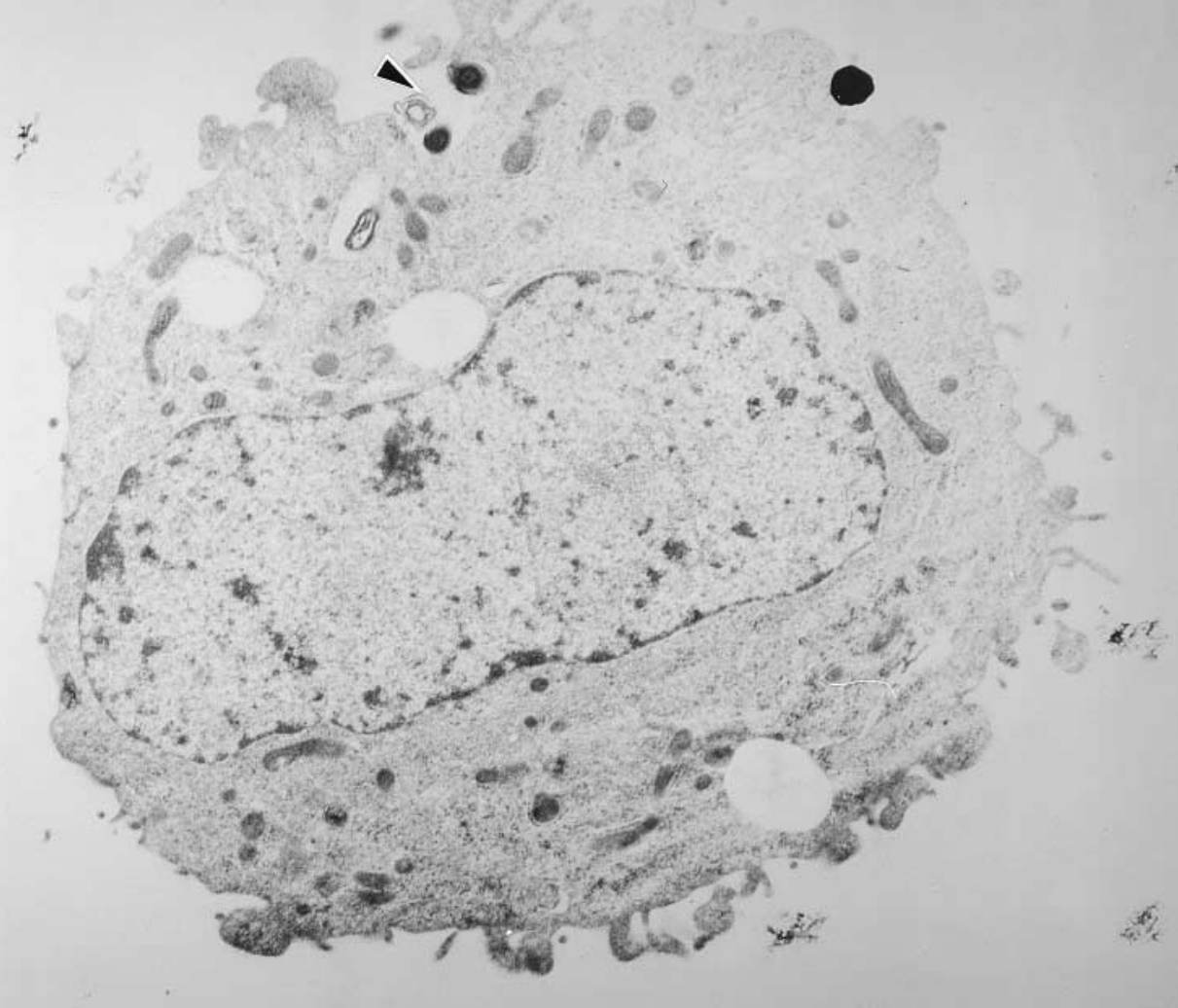

Fig. 1. (continued)

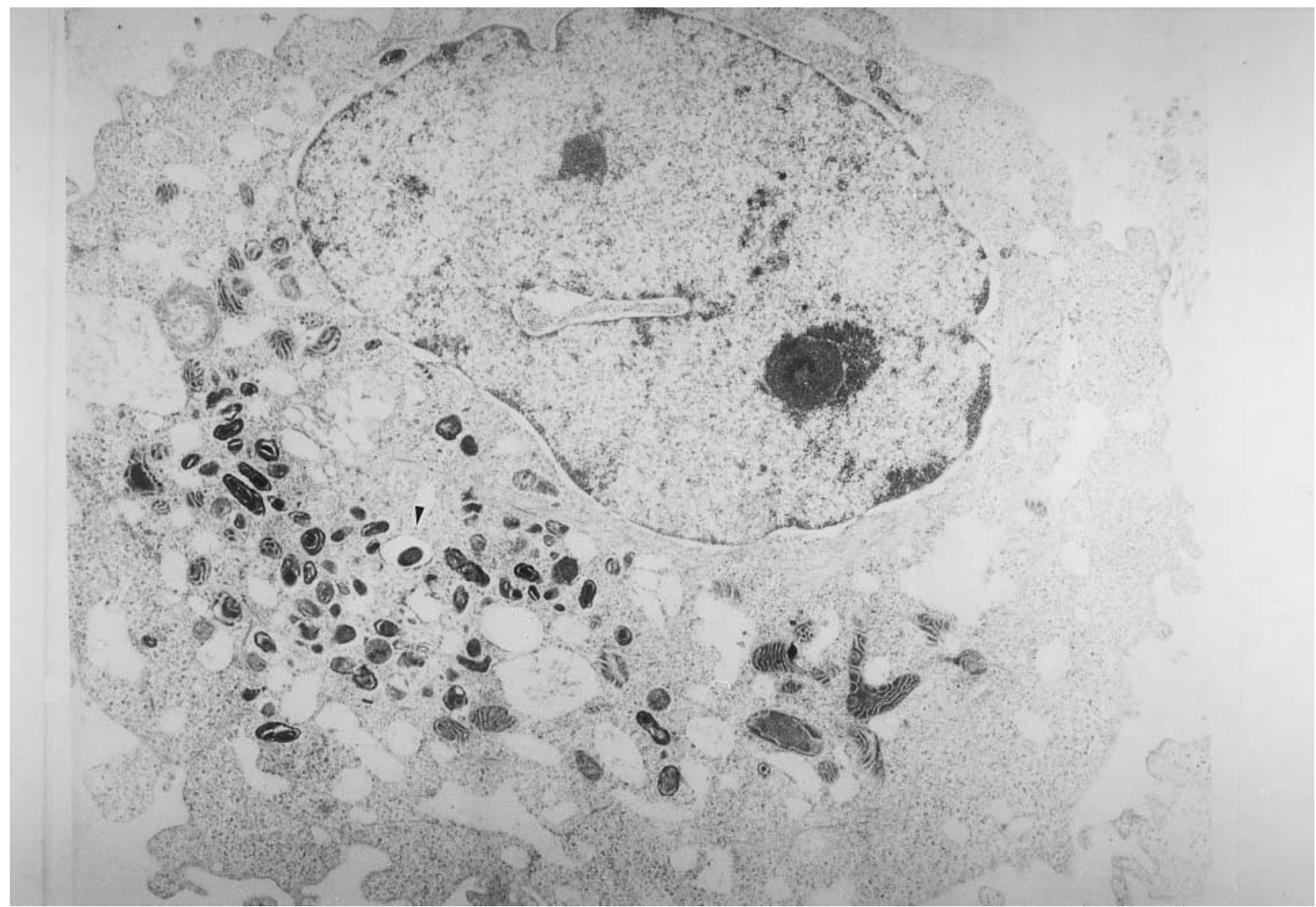

Fig. 2. Polarisation of organelles to the bacterial site within HT-29 cells was observed $24 \mathrm{~h}$ after infection of HT-29 cell monolayers. M. avium was seen within peri-nuclear vacuoles with a number of cell organelles surrounding it $(12400 \times)$. 

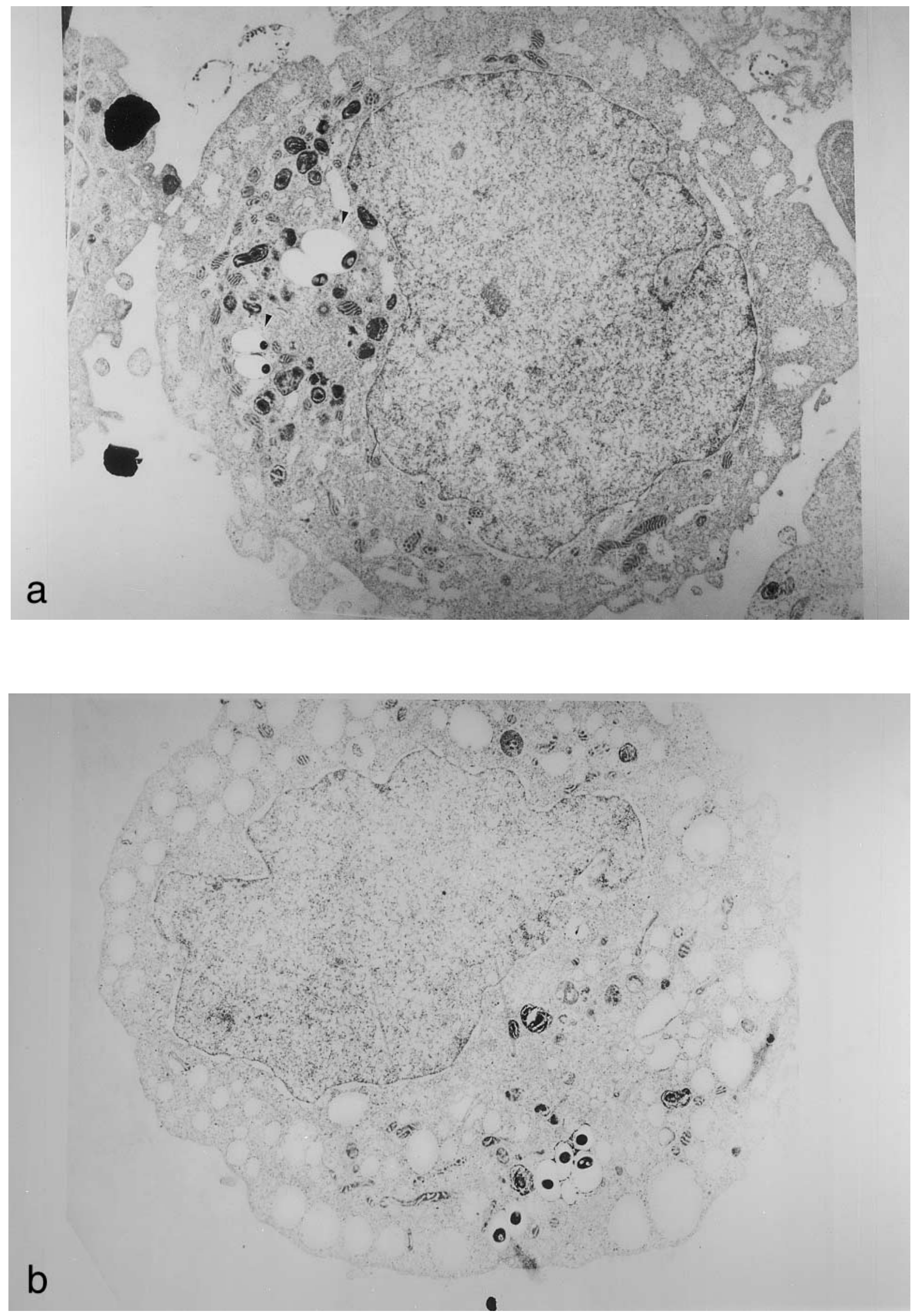

Fig. 3. M. avium within HT-29 cells $48 \mathrm{~h}$ after infection, showing: (a) segmentation of the vacuoles containing bacteria (arrows) and polarisation of organelles was similar to the observation in cells infected for $24 \mathrm{~h}$, although in a small number of cells $(12400 \times)$; (b) less marked organelle polarisation $(12400 \times)$; (c) segmentation of vacuoles at higher magnification $(55000 \times)$. 


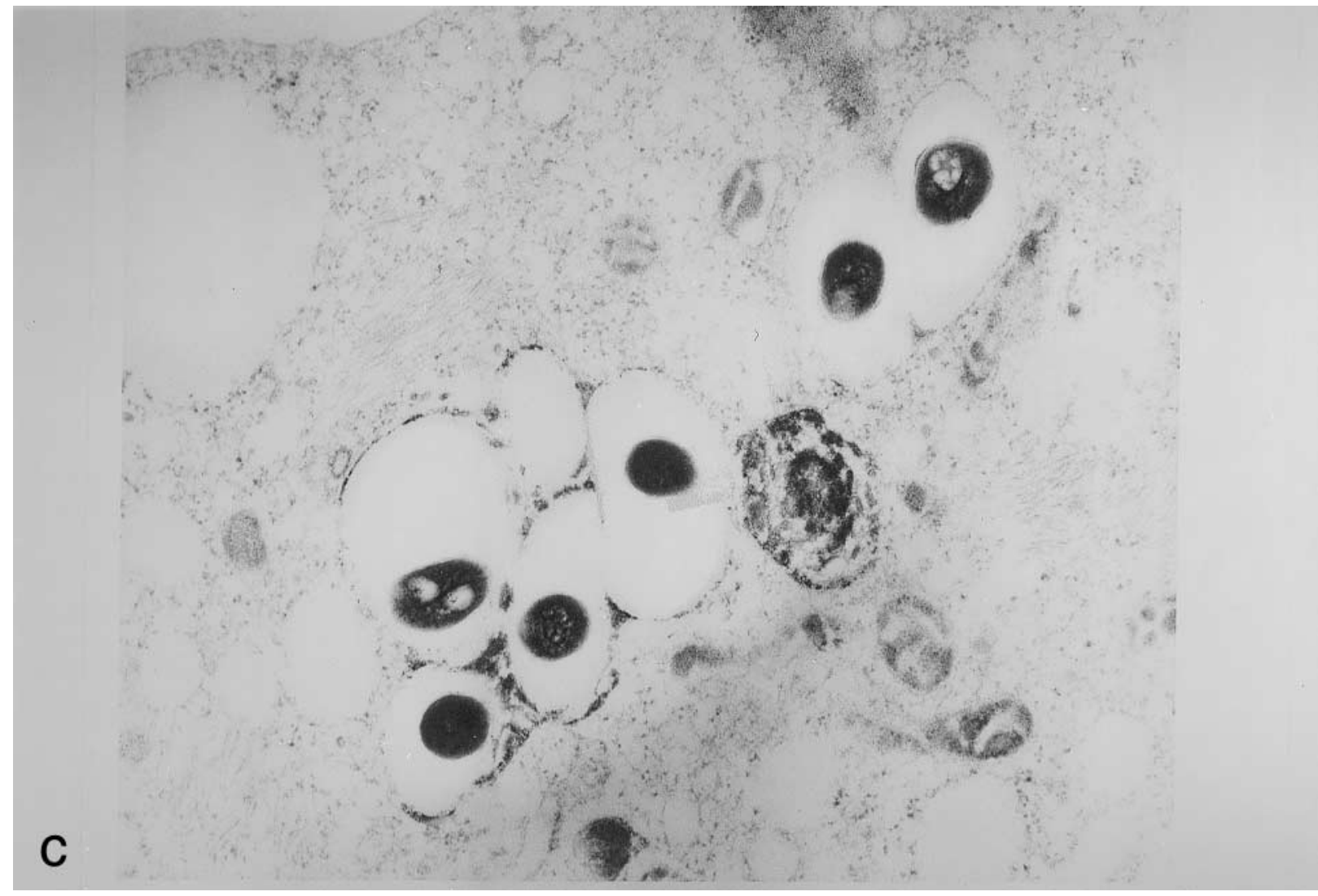

Fig. 3. (continued)

predominantly membrane protrusions that engulf the bacterium (Fig. 1a, b and c). Based on the present observations, the contact between the bacterium and the HT-29 cell can involve either only one tip or the entire body of the bacterium, suggesting that putative bacterial adhesin(s) must be expressed on the whole bacterial surface and not in a localised fashion as shown in recent studies on the mechanism of invasion of Listeria monocytogenes into epithelial cells. These studies demonstrated that the interaction between $\mathrm{L}$. monocytogenes and epithelial cells occurs through the bacterial tip [20]. It has been shown also that internalin, an L. monocytogenes invasive protein, is located in only one pole of the bacterium and does not spread on the bacterial envelope [20].

In the present study, a typical clathrin-mediated uptake of the bacteria, such as that observed with Chlamydia psittaci, was not observed [21]. The in-vitro studies showed that invasion of epithelial cells by $M$. avium results in re-arrangement of the cytoskeleton with actin polymerisation (data not shown).

Following uptake by intestinal epithelial cells, M. avium was encountered within cytoplasmic vacuoles, which underwent segmentation during the course of infection and tended to become single vacuoles containing only one bacterium by 5 days after infection. The vacuole was found close to the nucleus in most of the infected cells. This feature of mycobacterial vacuoles has also been described pre- viously in macrophages $[22,23]$; the explanation for this special characteristic remains to be elucidated. A nother feature of the $M$. avium lifestyle in epithelial cells is the size of the vacuole, i.e., $M$. avium lives intracellularly within large vacuoles. In contrast, $M$. avium vacuoles in macrophages have been observed to be smaller (sometimes just opposed to the bacterium) than the vacuoles in epithelial cells $[19,23]$. The reason for the difference in size between the vacuoles is currently unknown. Studies with other organisms such as Salmonella typhimurium have shown that this pathogen also lives inside large vacuoles [24]. It has been argued that large vacuoles, in contrast to tight vacuoles, are advantageous for the bacterium because they decrease the concentration of any intravacuolar bactericidal product delivery by the host cell.

In the present study, no extra-vacuolar bacteria were observed (in the cytoplasm). Two recent communications investigating intracellular $M$. tuberculosis (but not M. avium) within macrophages and type II alveolar epithelial cells have shown that the bacterium is capable of lysing the vacuole membrane and escaping into the cytoplasm $[25,26]$. However, these observations are controversial $[17,19,22,23]$ and the issue requires further investigation.

The fate of $M$. avium within epithelial cells in vitro is not known. A recent study of $M$. avium infection of macrophages has shown that apoptosis is a common event in infected cells [18]. Furthermore, it has been 

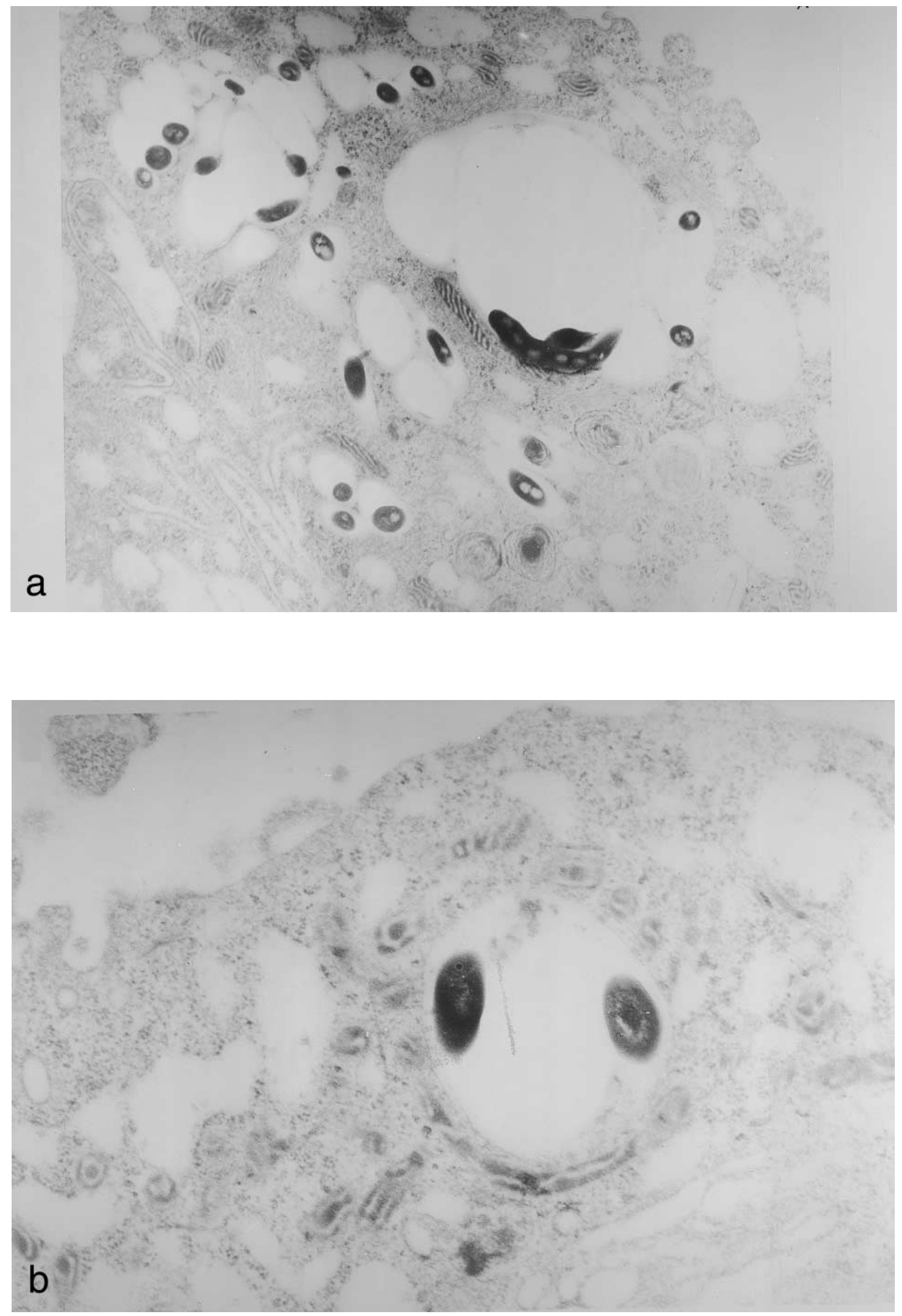

Fig. 4. M. avium apparently actively multiplying 5 days after infection. Organisms are seen within vacuoles that are undergoing division ( $a$ and b) (27500X and $25250 \times$ respectively). (c) A bacterium apparently undergoing division is seen in a large vacuole $(19250 \times)$. 


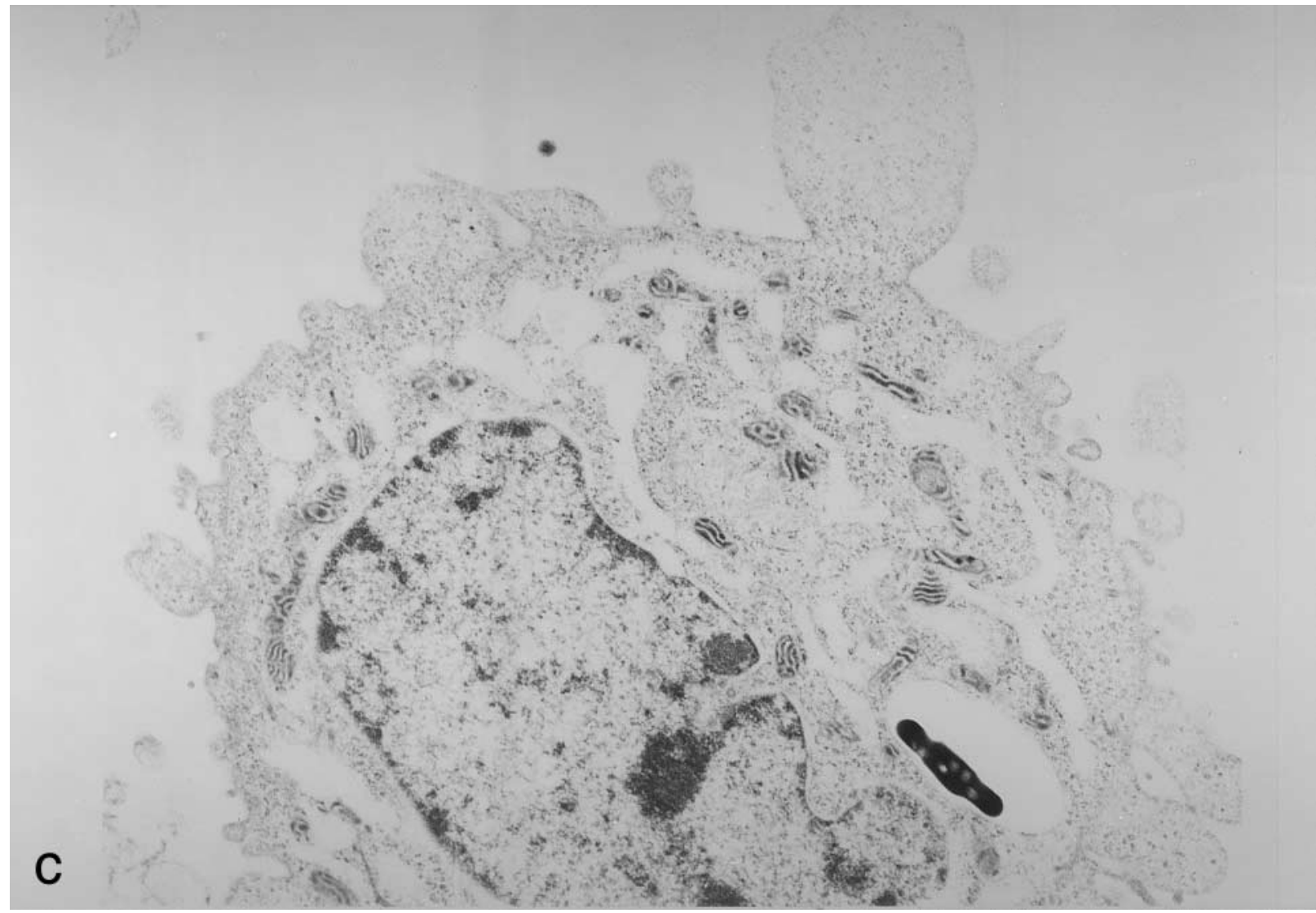

Fig. 4. (continued)

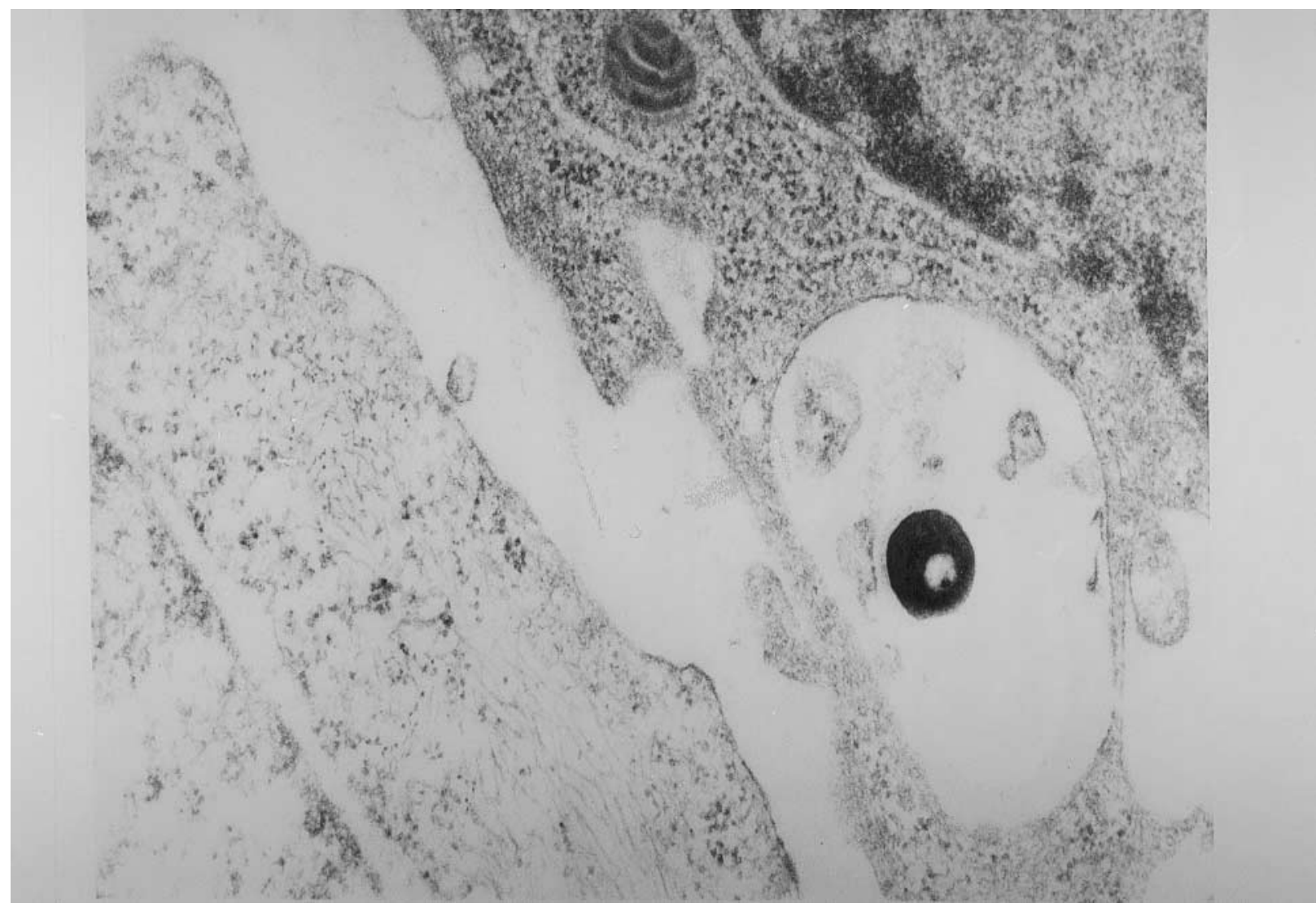

Fig. 5. M. avium vacuole within an HT-29 cell. The dark material suggests either bacterial or host cellular matter $(55000 \times)$. 
shown that $M$. avium organisms that leave macrophages undergoing apoptosis are capable of invading a second macrophage with increased efficiency [18]. A similar invasive bacterial phenotype was observed after passage within intestinal epithelial cells, although strong correlation with apoptosis cannot be made ( $F$. Sangari, L. E. Bermudez, unpublished observations). However, epithelial cell death and detachment following $M$. avium infection have been documented in the intestinal mucosa [27]. This finding, if confirmed by further studies, may be important in the understanding of the pathogenesis of $M$. avium infection of intestinal epithelial cells. Shigella, but not Listeria, cells have been demonstrated to invade epithelial cells by the basolateral pole $[28,29]$ and Shigella spp., as well as $L$. monocytogenes, have been shown to escape from infected epithelial cells $[30,31]$.

The observation that by $48 \mathrm{~h}$ the mycobacterial vacuoles contained detached matter is in agreement with previous results [32], although the significance of this finding is currently unknown.

These results suggest a specific interaction between $M$. avium and epithelial mucosal cells, showing that $M$. avium is well adapted to survive and replicate in, and perhaps escape from, intestinal mucosal cells.

We thank Karen Allen for preparing this manuscript.

\section{R eferences}

1. Benson CA, Ellner JJ. Mycobacterium avium complex infection and AIDS: advances in theory and practice. Clin Infect $D$ is 1993; 17: 7- 20.

2. Horsburgh CR. Mycobacterium avium complex in the acquired immunodeficiency syndrome. N Engl J Med 1991; 324: 13321338.

3. Inderlied CB, Kemper CA, Bermudez LEM. The Mycobacterium avium complex. Clin Microbiol Rev 1993; 6: 266-310.

4. Damsker B, Bottone EJ. Mycobacterium avium-M ycobacterium intracellulare from the intestinal tracts of patients with the acquired immunodeficiency syndrome: concepts regarding acquisition and pathogenesis. J Infect Dis 1985; 151: 179-181.

5. Jacobson MA, Hopewell PC, Yajko DM et al. Natural history of disseminated Mycobacterium avium complex infection in AIDS. J Infect Dis 1991; 164: 994-998.

6. Bermudez LE, Young LS. Factors affecting invasion of HT-29 and $\mathrm{HEp}-2$ epithelial cells by organisms of the Mycobacterium avium complex. Infect Immun 1994; 62: 2021-2026.

7. Hsu N, Goodman JR, Young LS, Bermudez LE. Interaction between Mycobacterium avium complex and intestinal mucosal cells in vivo. Proceedings of the 36th ICAAC. A merican Society for Microbiology 1996

8. $M$ apother $M E$, Songer JG. In vitro interaction of Mycobacterium avium with intestinal epithelial cells. Infect Immun 1984; 45: $67-73$.

9. Bermudez LE, Sangari FJ, Petrofsky M, Goodman JR. Mycobacterium avium invasion of intestinal mucosal cells occurs more frequently through enterocytes than $M$ cells and primarily by interaction with glycoconjugates (abstract). Molecular Signals and Infectious Diseases. Paris, Institut Pasteur. 1998

10. Fujimura $Y$. Functional morphology of microfold cells ( $M$ cells) in Peyer's patches: phagocytosis and transport of BCG by $M$ cells into rabbit Peyer's patches. Gastroenterol J pn 1986; 21: $325-335$.

11. Sturgill-Koszycki S, Schlesinger PH, Chakraborty P et al. Lack of acidification in Mycobacterium phagosomes produced by exclusion of the vesicular proton-ATPase. Science 1994; 263 678-681.

12. Huet C, Sahuquillo-M erino C, Coudrier E, Louvard D. Absorptive and mucous-secreting subclones isolated from a multipotent intestinal cell line (HT-29) provide new models for cell-polarity and terminal differentiation. I Cell Biol 1987; 105: $345-357$

13. Finlay BB, Gumbiner B, Falkow S. Penetration of Salmonella through a polarized Madin-Darby canine kidney epithelial cell monolayer. J Cell Biol 1988; 107: 221-230.

14. Clerc PL, B erthon B, Claret M, Sansonetti PJ. Internalization of Shigella flexneri into Hela cells occurs without an increase in cytosolic $\mathrm{Ca}^{2+}$ concentration. Infect Immun 1989; 57: 2919- 2922.

15. Gaillard J-L, Berche P, M ounier J, Richard S, Sansonetti P. In vitro model of penetration and intracellular growth of Listeria monocytogenes in the human enterocyte-like cell line - Caco2. Infect Immun 1987; 55: 2822-2829.

16. Inderlied CB, Kolonoski PT, Wu M, Young LS. In vitro and in vivo activity of azithromycin (CP 62, 993) against the Mycobacterium avium complex. J Infect Dis 1989; 159: 994- 997.

17. Bermudez LE, Goodman J. Mycobacterium tuberculosis invades and replicates within type II alveolar cells. Infect Immun 1996; 64: 1400-1406.

18. Bermudez LE, Parker A, Goodman JR. Growth within macrophages increases the efficiency of Mycobacterium avium to invade other macrophages by a complement receptor independent pathway. Infect Immun 1997; 65: 1916-1925.

19. de Chastellier $C$, Lang T, Thilo L. Phagocytic processing of the macrophage endoparasite, Mycobacterium avium, in comparison to phagosomes which contain Bacillus subtilis or latex beads. Eur | Cell Biol 1995; 68: 167-182.

20. Lebrun $M, M$ engaud J, Ohayon $H, N$ ato $F$, Cossart $P$. Internalin must be on the bacterial surface to mediate entry of Listeria monocytogenes into epithelial cells. Mol Microbiol 1996; 21: 579- 592.

21. Vanrompay D, Charlier G, Ducatelle R, Haesebrouck F Ultrastructural changes in avian Chalmydia psittaci serovar A-, B-, and D-infected buffalo green monkey cells. Infect Immun 1996; 64: 1265-1271.

22. Clemens DL, Horwitz MA. Characterization of the Mycobacterium tuberculosis phagosome and evidence that phagosoma maturation is inhibited. I Exp Med 1995; 181: 257-270.

23. Xu S, Cooper A, Sturgill-Koszycki $S$ et al. Intracellular trafficking in Mycobacterium tuberculosis and Mycobacteriumavium-infected macrophages. J Immunol 1994; 153: 25682578.

24. Alpuche-A randa CM, Racoosin EL, Swanson JA, Miller SI Salmonella stimulate macrophage macrophinocytosis and persist within spacious phagosomes. J Exp Med 1994; 179: 601608.

25. $M C D$ onough $K A, K$ ress $Y, B l o o m ~ B R$. Pathogenesis of tuberculosis: interaction with macrophages. Infect Immun 1993; 61: 2763-2773.

26. Mehta PK, King $\mathrm{CH}$, White EH, Murtagh JJ, Quinn FD. Comparison of in vitro models for the study of Mycobacterium tuberculosis invasion and intracellular replication. Infect Immun 1996; 64: 2673-2679.

27. Kim SY, Goodman JR, Petrofsky M, Bermudez LE. Mycobacterium avium infection of the gut mucosa in mice associated with late inflammatory response and intestinal cell necrosis. J Med Microbiol 1998; 47: 725-731.

28. Karunasagar I, Senghaas B, Krohne G, Goebel W. Ultrastructural study of Listeria monocytogenes entry into cultured human colonic epithelial cells. Infect Immun 1994; 62: 3554-3558.

29. Mounier J, Vasselon T, Hellio R, Lesourd M, Sansonetti PJ. Shigella flexneri enters human colonic Caco-2 epithelial cells through the basolateral pole. Infect Immun 1992; 60: 237-248.

30. Mounier J, Ryter A, Coquis-Rondon M, Sansonetti PJ. Intracellular and cell-to-cell spread of Listeria monocytogenes involves interaction with $\mathrm{F}$-actin in the enterocyte-like cell line Caco-2. Infect Immun 1990; 58: 1048- 1058.

31. Parsot C. Shigella flexneri: genetics of entry and intracellular dissemination in epithelial cells. Curr Top Microbiol Immunol 1994; 192: 217- 241.

32. Frehel $C$, de Chastellier C, Lang T, Rastogi N. Evidence for inhibition of fusion of lysosomal and prelysosomal compartments with phagosomes in macrophages infected with 